\title{
Conservation genomics of Atlantic salmon: SNPs associated with QTLs for adaptive traits in parr from four trans-Atlantic backcrosses
}

\author{
EG Boulding ${ }^{1}$, M Culling ${ }^{1}$, B Glebe ${ }^{2}$, PR Berg 3 , S Lien ${ }^{3,4}$ and T Moen ${ }^{3,5}$ \\ ${ }^{1}$ Department of Integrative Biology, University of Guelph, Guelph, Ontario, Canada; ${ }^{2}$ Department of Fisheries and Oceans, St Andrews \\ Biological Station, St Andrews, New Brunswick, Canada; ${ }^{3}$ CIGENE_Centre for Integrative Genetics, Norwegian University of Life \\ Sciences, Ass, Norway; ${ }^{4}$ Department of Animal and Aquacultural Sciences, Norwegian University of Life Sciences, Ås, Norway and \\ ${ }^{5}$ AKVAFORSK-The Institute for Aquaculture Research, As, Norway
}

European Atlantic salmon (Salmo salar) differ in skin pigmentation and shape from the North American lineage of Atlantic salmon but the genetic basis of these differences are poorly understood. We created four large $(N=300)$ backcross families by crossing F1 hybrid male siblings to two females from the European and two from the North American aquacultural strains. We recorded 15 morphological landmarks and two skin pigmentation, three growth and three condition traits on parr. The backcross families were genotyped for at least 129 SNPs (single nucleotide polymorphisms) within expressed sequence tags (ESTs) spaced throughout the Atlantic salmon linkage map. The high polymorphism and low rates of crossover in our hybrid sires provided enough statistical power to detect 79 significant associations between SNP markers and quantitative traits after experiment-wide permutation analysis for all families within traits. Linkage group AS22 contained a quantitative trait loci (QTL) for parr mark number; its homolog AS24 contained a large QTL, which explained $26 \%$ of the phenotypic variance in parr mark contrast. We found 25 highly significant QTLs for body shape and fin position on seven different linkage groups, and 16 for growth and condition on six different linkage groups. QTL(s) for pectoral fin position, caudal peduncle position, late parr growth and condition index were associated with an SNP on linkage group AS1, which was linked to the sex-determining locus. Our work adds to the evidence that much of the variation in growth rate, shape and skin pigmentation observed among Atlantic salmon parr from different natal streams is genetic.

Heredity (2008) 101, 381-391; doi:10.1038/hdy.2008.67; published online 23 July 2008

Keywords: candidate genes; ESTs; geometric morphometrics; juvenile growth; parr marks; Salmo salar

\section{Introduction}

Quantitative trait loci (QTL) have been found for a large number of agriculturally important traits but few studies have searched for QTLs for adaptive traits that differ among different wild populations (Slate, 2005). This is a bit surprising because QTL mapping of wild animal species can also be performed by crossing genetically diverse strains and following the coinheritance of phenotypic traits and the markers in different families (Lynch and Walsh, 1998). The most likely explanation is that few molecular markers are available for most wild species making genome scanning impossible unless preceded by extensive marker development. Consequently, most QTLs that have been detected so far have been for wild species closely related to model organisms or agriculturally important species whose linkage maps have a high marker density (reviewed by Slate, 2005). However, QTLs for plate armour, gill rakers and spine length (Nereng et al., 2001; Colosimo et al., 2004) and

Correspondence: Dr EG Boulding, Department of Integrative Biology, University of Guelph, 50 Stone Road East, Guelph, Ontario, Canada N1G 2W1.

E-mail: boulding@uoguelph.ca

Received 25 August 2007; revised 25 May 2008; accepted 20 June 2008; published online 23 July 2008 shape (Albert et al., 2008) have been detected in the F2 generations of crosses between two morphologically divergent populations of wild stickleback fishes. Additionally, separate QTLs for jaw opening and closing levers have been detected in the F2 of a cross between a heavy-jawed and slender-jawed species of cichlid fish from Lake Malawi (Albertson et al., 2005).

The Atlantic salmon (Salmo salar) is important to the sports fishing and aquacultural industries, so its genome has been extensively studied even though its large genome size and large number of chromosomes are less than ideal. The North American populations typically have a $2 \mathrm{~N}$ number of 54 chromosomes, whereas the European populations typically have a $2 \mathrm{~N}$ number of 58 chromosomes; the $1.5 \% \mathrm{mtDNA}$ control region sequence divergence between two lineages suggests that they have evolved independently for 600000 years (King et al., 2007). The genome size of the Atlantic salmon is larger than that of most teleost fishes (average $2 \mathrm{~N}=48$ ) and is believed to have resulted from a tetraploidization event in a common ancestor of the salmonid fishes living about 60 million years ago (Allendorf and Thorgaard, 1984). Despite these challenges, three low-resolution linkage maps have been published for Atlantic salmon, one based on microsatellite (STR) markers (Gilbey et al., 2004), one based on AFLP and microsatellite markers (Moen et al., 2004) and one based on microsatellite 
markers and SNP markers (Moen et al., 2008). As a result, we know that the Atlantic salmon has one of the largest differences in the recombination rates between the two sexes with an average of 8.3 female recombination events to every male recombination event (Moen et al., 2004). Now there is also a physical map of the Atlantic salmon genome ( $\mathrm{Ng}$ et al., 2005). However, both a higherresolution linkage map and a completely sequenced genome will need to be publicly available before salmon genomics can make the transition from QTL association (linkage disequilibrium) mapping to molecular identification of at least some of the causal mutations. The presence of a well-annotated genome sequence permits in silico data-mining searches for causal mutations that are in the right location to be the detected QTL. Such an approach has resulted in the identification of causal mutations, or quantitative trait nucleotides (QTNs), responsible for quantitative trait variation in several agriculturally important animal species (Ron and Weller, 2007).

Single nucleotide polymorphisms (SNP) are less polymorphic than microsatellite markers but are more abundant, more easily multiplexed and can often be automatically scored (Koljonen et al., 2007). SNPs can be discovered even in poorly studied species, by designing degenerate primers in conserved regions of proteincoding genes using comparative alignments of DNA sequences from related species (for example, Tao and Boulding, 2003). In better studied species, large numbers of SNPs in protein-coding genes can be discovered by aligning cDNA sequences from expressed sequence tag (EST) libraries (for example, Hayes et al., 2007). A statistical association between specific alleles of an SNP and the trait of interest can occur for three reasons: (1) because the gene is directly involved in the genetic control of the trait, (2) because the functional polymorphism is tightly physically linked to the SNP marker or (3) because the SNP locus is in linkage disequilibrium with the functional polymorphism because of past selective sweeps, population bottlenecks or the recent creation of a geographic barrier to gene flow (Lynch and Walsh, 1998).

Identification of combinations of functional molecular polymorphisms that differ in frequencies among populations inhabiting different environments could facilitate the conservation of endangered species. For example, better understanding of the molecular genetic basis of local adaptation by juvenile Atlantic salmon (or parr) to their natal rivers would allow better definition of conservation units and provide information on which populations should be targeted for captive breeding programs. Heritable variation between and within populations has been well documented for traits important in salmonid aquaculture such as body size, feeding behaviour, growth rate, muscle growth, survival, disease resistance and age at sexual maturity (reviewed by Garcia de Leaniz et al., 2007). However, other traits suspected to be under strong diversifying selection in wild populations, such as skin pigmentation and body form, have received much less attention.

Parr marks are vertical bars or blotches of melanin found on the sides of juvenile salmonids, which have been shown to be important in crypsis of juvenile salmon against river substrates of different sizes and types (Donnelly and Dill, 1984). To some extent juvenile salmon can change their skin pigmentation to better match their environment, which can reduce their mortality from avian predators (reviewed by Donnelly and Whoriskey, 1993). Nevertheless, the number of parr marks has been shown to be heritable within a population of masou salmon (Kudo et al., 2002).

Interpopulation differences in head and body shape are known to be correlated with the stream gradient as well as the continent of origin (Claytor et al., 1991). These differences in shape persist in a common environment, suggesting that they are partially genetic in origin (Riddell and Leggett, 1981; Nicieza, 1995). Even newly emerged Atlantic salmon parr showed significant interpopulation differences in body form, eye and mouth sizes, and fin position and length (Solem et al., 2006). On the other hand, body shape of Atlantic salmon parr is known to be phenotypically plastic and to change significantly only after 1 month at higher flow velocities (Pakkasmaa and Piironen, 2001). Therefore, it would be useful to know whether the phenotypic variation in these important adaptive traits has a small or a large genetic component and whether the genetic component is determined by many genes of small effect or by a few major loci of large effect.

In this paper, we identify SNP markers on particular linkage groups that are associated with QTLs for growth rate, condition factor, shape and skin pigmentation traits in juvenile Atlantic salmon. QTLs for growth rate and condition factor have been mapped in juvenile Atlantic salmon before (reviewed by Reid et al., 2005 and Moghadam et al., 2007a). However, as far as we know (Garcia de Leaniz et al., 2007), we are the first to search for QTLs for parr mark number and contrast. We also believe that ours is the first study to look for QTLs for shape in salmonid fishes using modern techniques of geometric morphometrics (Rohlf, 2002).

\section{Materials and methods}

\section{Study populations}

All fish were held at the Department of Fisheries and Oceans Biological Station (SAB) in St Andrews, New Brunswick, Canada. In November 2003, a large full-sib family of trans-Atlantic F1 hybrids was created by crossing a Norwegian Mowi aquacultural strain female to a Canadian Saint John's aquacultural strain male. In November 2005, four full-sibling backcross families were created by crossing precocious trans-Atlantic hybrid male parr to two females from each of the Norwegian Mowi and the Canadian Saint John's parental strains (Table 1). These fish have a male parent that is a hybrid between two highly divergent lineages of Atlantic salmon, which resulted in at least one family showing scorable segregating polymorphisms at 67 of the 129 SNP marker loci that were genotyped for families B-D. This high level of polymorphism at the SNP loci (Koljonen et al., 2007) and likely also at many QTL loci combined with the low rate of crossover in salmonid males made these backcross families especially useful for the coarse mapping of genes underlying important complex traits to a particular chromosome arm (Hayes et al., 2006).

The offspring from all four back crosses and from two pure bred crosses were raised in the same initial density and under the same environmental conditions. The 
Table 1 Details of four backcrosses and two purebred crosses between Canadian Saint John River aquacultural strain (SJ) and Norwegian Mowi aquacultural strain (Mw)

\begin{tabular}{|c|c|c|c|c|c|c|}
\hline Cross (no.) & Male & Female & Spawned & $W 1$ (s.d.) $\mathrm{N}^{\mathrm{a}}$ & No. of SNP loci genotyped & No. of fish genotyped $^{\mathrm{b}}$ \\
\hline A (SAB516) & $\mathrm{F} 1^{\mathrm{c}}$ & SJ & 22 November $2005^{\mathrm{d}}$ & 11.9 (1.16) 285 & 320 & 286 \\
\hline B (SAB751) & $\mathrm{F} 1^{\mathrm{c}}$ & SJ & 22 November $2005^{\mathrm{d}}$ & 16.1 (1.16) 136 & 129 & $134^{\mathrm{e}}$ \\
\hline C (SAB762) & $\mathrm{F} 1^{\mathrm{c}}$ & Mw & 18 November $2005^{\mathrm{f}}$ & 8.00 (1.15) 297 & 129 & 282 \\
\hline D (SAB557) & $\mathrm{F} 1^{\mathrm{c}}$ & Mw & 18 November $2005^{\mathrm{f}}$ & 13.3 (1.15) 285 & 129 & 280 \\
\hline E (SAB518) & SJ & SJ & 22 November $2005^{\mathrm{d}}$ & 12.2 (1.16) 30 & 129 & 2 \\
\hline F (SAB714) & Mw & Mw & 18 November $2005^{\mathrm{f}}$ & 13.7 (1.16) 31 & 129 & 2 \\
\hline
\end{tabular}

Weight at measurement time 1 (W1) and maximum number of SNP loci and number of progeny that were successfully genotyped in each cross is also shown.

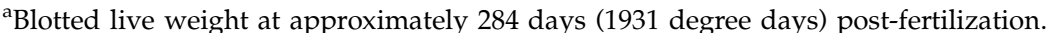

${ }^{\mathrm{b}}$ Also genotyped parents and paternal grandparents of each cross.

${ }^{c}$ F1 hybrids were all full siblings spawned in November 2003 using a Mw female and a SJ male.

${ }^{\mathrm{d}}$ The pure Norwegian Mowi strain crosses (family F) and backcrosses (families C and D) with Mowi/Saint John hybrid precocious males were completed and placed in the Heath incubators at $4{ }^{\circ} \mathrm{C}$ on 18 November 2005 at SABS. On 22 November, pure Saint John aquacultural strain egg lots were picked up at Cooke Aquaculture's Oak Bay (NB) hatchery along with the unfertilized eggs from four Saint John aquacultural strain females. The unfertilized eggs were crossed with F1 hybrid Mowi/Saint John precocious males at SABS and incubated at $4{ }^{\circ} \mathrm{C}$ in Heath incubators to create backcross families A and B. The pure Saint John crosses obtained from Oak Bay did not survive, so on 13 January 2006 these crosses were replaced by another five from Oak Bay to form pure strain Saint John family E.

${ }^{\mathrm{e}}$ Family B was killed and phenotypically sexed after the third measurement period.

${ }^{\mathrm{f}}$ From spawning to the first measurement period (30 August to 4 September 2006) was 284 days or 1931 degree days post-fertilization.

surviving purebred crosses (Table 1) consisted of one pure Saint John cross (family E) and one pure Norwegian Mowi strain crosses (family F). Initially all crosses were placed in Heath incubators at $4{ }^{\circ} \mathrm{C}$. On 10-13 February 2006, the alevins were transferred from the Heath incubators to $1 \mathrm{~m}$ diameter circular fibreglass tanks for their first feeding on brine shrimp. Each full-sib family was put into a separate circular tank. At this point, the water temperature was slowly increased to $14^{\circ} \mathrm{C}$ to stimulate first feeding, as is the commercial production practice in Eastern Canada. The fish were then pit-tagged and moved to a large $3 \mathrm{~m}$ diameter communal tank during the first measurement period (30 August 30 to 4 September 2006). By the time the largest individuals in these four backcross families of fish had reached the smolt stage of their life history in May 2007, all juveniles had been weighed, measured and photographed three times and genotyped for at least 129 SNP markers (Table 1). The mean and variance for weight at measurement time one were very similar among the four families (Table 1).

The data analysis that we describe below tested whether EST derived-SNP markers were associated with QTLs for body weight (BW), condition factor (K) for three different measurement periods. Fulton's condition factor $(\mathrm{K})$ was calculated as $\left(100 \times \mathrm{BW} \times \mathrm{FL}^{-3}\right)$. For the first measurement period only, we also looked for SNPS that were associated with shape using geometric morphometric characterization of 15 landmarks (Rohlf, 2002) and characterized the number and relative brightness of the parr marks.

\section{Morphological data}

Approximately 300 parr from each of four backcross populations were measured at SABS on 30 August to 4 September 2006. Each fish was anaesthetized (Aquacalm which is metomidate hydrochloride; sedation concentrations: $0.25-1 \mathrm{mg}$ of metomidate per liter of water), weighed, and then positioned laterally, left side up, on a measured grid page where the length, and a digital image of each individual was recorded (Olympus
Camedia 3040 ZOOM camera with 3.2 mega pixels resolution). All photographs were taken from the same angle with the same ruler included in all photographs for scaling.

Landmark-based geometric morphometrics (Rohlf, 2002) were used to acquire shape data from the photographs. Fifteen landmarks (Supplementary Figure 1) were digitized on each image using tpsDig 2.06 (Rohlf, 2006; http://life.bio.sunysb.edu/morph/index. html). The landmarks were chosen to capture the overall body shape with as few variables as possible, because the power of geometric morphometric analysis is inversely proportional to the number of landmarks for a given number of specimens. A further criterion for the choice of landmarks was that they should capture morphological traits that have shown variation in earlier studies of Atlantic salmon (for example, Claytor and MacCrimmon, 1988).

The following landmarks were digitized: (1) tip of snout, (2) anterior beginning of lateral line, (3) anterior insertion of dorsal fin, (4) anterior insertion of adipose fin, (5) dorsal insertion of caudal fin, (6) most posterior midpoint of caudal peduncle, (7) fork point in caudal fin, (8) ventral insertion of caudal fin, (9) anterior insertion of anal fin, (10) anterior insertion of pelvic fin, (11) most posterior point of pectoral fin, (12) ventral and more dorsal (13) insertions of pectoral fin, (14) point where operculum joins the outline of body (ventral) and (15) most anterior point of pupil (Supplementary Figure 1).

We also used the photographs to count the number of parr marks on the side of each fish. To quantify the contrast of the parr mark against the lighter skin, we used the eyedropper tool in Adobe Photoshop 7.0. For each image, a $5 \times 5$ pixel brightness measure was taken from the centre of each parr mark using the eyedropper tool (Supplementary Figure 2). Moving anteriorly from the measured parr mark, a second skin background $(5 \times 5$ pixels) brightness measure was recorded from the midpoint between two successive parr marks along the lateral line. The two types of measured values were recorded as parr mark and skin brightness values for each of the visible parr marks along the fish's body 
(Supplementary Figure 2). Contrast values for each parr mark were then calculated as the ratio of the skin colour brightness to the respective parr mark brightness value, as suggested by Marit Gjerstad of PhotoFish of As, Norway (e-mail to EGB). The skin is always brighter than the parr mark, so the ratio is always greater than one and becomes larger the darker the parr mark is. Brightness values were recorded and contrast values were calculated for each parr mark along the body. The resulting contrast values were then averaged and used to find the mean colour contrast value of a particular fish. To quantify phenotypic differences in shape and skin pigmentation between the two lineages, we also photographed 30 parr of the pure Saint John's strain and 30 parr of the pure Mowi strain that had been reared under the same conditions as our backcrosses (Table 1).

Aligned $\mathrm{x}$ and $\mathrm{y}$ coordinates were obtained using tpsRegr 1.31 (Rohlf, 2005), which aligns, scales and rotates the digitized landmark configurations using generalized orthogonal least-squares procrustes procedures (Rohlf, 2002). The 15 aligned $x$ and $y$ coordinates of the landmarks on the superimposed specimens were used as shape variables in our subsequent QTL statistical analyses even though some coordinates were correlated. We used aligned $x$ and $y$ shape coordinates as it has recently been done for sticklebacks (Albert et al., 2008), rather than principal components, because the coordinates better approximate chemical gradients in the developing teleost embryo caused by position-specific expression of different genes (for example, Eivers et al., 2004).

\section{Molecular data}

Coarse mapping of QTLs associated with our phenotypic traits in backcross family A was carried out using 320 SNP loci that were already developed for Atlantic salmon (Moen et al., 2008). The methods of SNP discovery by aligning published EST sequences from Atlantic salmon (for example, Rise et al., 2004) and processing the contiguous cDNA sequences has been described in detail elsewhere (Hayes et al., 2007). A linkage map of 304 of these SNPs, along with 138 microsatellites, has been constructed for a Norwegian aquacultural strain of salmon (Moen et al., 2008). The linkage group nomenclature used here corresponds to that used in the ASalBASE Atlantic salmon linkage map 'powered by cGRASP' (http://www.asalbase.org/sal$\mathrm{bin} / \mathrm{map} /$ index). The hybrid parents in these four backcrosses were males and therefore exhibited crossover rates that were close to zero across the genome, except for regions very close to telomeres (Moen et al., 2004, 2008). Therefore, the remaining families B, C and D were genotyped for only two SNP-EST loci per linkage group. A linkage map of the 67 SNPs that were polymorphic in at least one of the four families was constructed for the hybrid sires then used in the QTL Express analysis (Supplementary Appendix 2).

The MassArray TM system from Sequenom (San Diego, CA, USA) was used to carry out SNP genotyping. To make the multiplexes, PCR primers and extension primers were designed using the software SpectroDESIGNER v3.0 (Sequenom). Family A was genotyped for 320 SNP-EST loci using 15 separate PCR reactions with multiplexing levels that were between 20 and 29 (primers in Moen et al., 2008 http://www.biomedcentral.com/imedia/2786797671828521/supp1.xls). This was followed by the primer extension iPLEX protocol, suggested by Sequenom (available at http://www. sequenom.com). Allele separations were performed using the Sequenom MassARRAY Analyzer (Autoflex mass spectrometer). On the basis of the mass peaks present, genotypes were assigned in real time (Tang et al., 1999) using the MassARRAY SpectroTYPER RT v3.4 software (Sequenom). Finally, manual inspection of all the results by the first author was carried out using the MassARRAY TyperAnalyzer v3.3 software (Sequenom). Families B, C and D were genotyped for only two SNPEST loci per linkage group using four separate PCR reactions with multiplexing levels that were between 29 and 34 (Supplementary Appendix 1). This higher level of multiplexing was possible because it was followed by the new primer extension iPLEX GOLD chemistry, which is now available from Sequenom (http://www.sequenom. com).

\section{QTL analysis}

Single QTL analysis was carried out with QTL Express (http:/ / qtl.cap.ed.ac.uk/) using $1.0 \mathrm{cM}$ distances and the defaults for this two-way backcross design (Seaton et al., 2002). This programme assumes that each offspring inherits one of two alternative alleles at the putative QTL from its hybrid male parent. In terms of the programme, our BC1 population is the progeny of an F1 male and Saint John's female, and our BC2 populations are the progeny of an F1 male and Mowi female. The reciprocal backcross design with the two shared paternal grandparents allowed separation of additive variance from dominance variance but did not allow estimation of interaction variance. The allele substitution effect is the difference in value between the homozygous (or recurrent) QTL genotype and the heterozygous genotype and contains both an additive and a dominance portion (http://qtl.cap.ed.ac.uk/). If the allele substitution effect is positive then the effect of the homozygous QTL genotype is larger than the effect of the heterozygous genotype. Experimentwise significance of putative QTL at $\alpha=0.05$ and at $\alpha=0.01$ was evaluated separately for each trait using the permutation test option with 250 permutations. Some of our largest QTLs would have shown experimentwise significance at $\alpha=0.001$ but the programme does not evaluate this level. We included composite size as a covariate to our QTL analyses of shape to correct for possible allometric size. This covariate was not significant in most analyses, perhaps because the data had already been corrected for isometric size by tpsRegr (Rohlf, 2005) when the landmarks were aligned.

\section{Results}

A total of 1002 fish were measured for each trait during the first measurement period and 876 of these were still alive during the third measuring period. Nearly all of the traits were normally distributed except for parr mark contrast and condition factor and these were normal after transformation (Table 2). The number of parr marks ranged from 1 to 12 but had a mode of 9 . We also found that there were differences in skin pigmentation and shape between the two parental strains even though both 
Table 2 Means (standard deviations) for raw and transformed trait measurements at three different measurement times: 1 (1931 degree days), 2 (4332 degree days) or 3 (5368 degree days) post-fertilization

\begin{tabular}{|c|c|c|c|c|c|c|c|}
\hline Trait $^{\mathrm{a}}$ & Mean & s.d. & $\mathrm{N}$ & Skewness & Kurtosis & Min & $\operatorname{Max}$ \\
\hline L1 & 10.36 & 1.45 & 1007 & 0.24 & -0.39 & 7.10 & 14.90 \\
\hline W1 & 11.70 & 4.79 & 1005 & 0.83 & 0.79 & 3.80 & 31.20 \\
\hline cubeW1 & 1.41 & 0.08 & 1005 & -0.01 & -0.51 & 1.21 & 1.65 \\
\hline K1 & 1.00 & 0.14 & 1005 & 5.47 & 63.53 & 0.49 & 3.01 \\
\hline CI1 & 0.14 & 0.01 & 1005 & 0.36 & -0.06 & 0.11 & 0.19 \\
\hline L2 & 12.05 & 1.86 & 947 & -0.32 & -0.71 & 7.10 & 16.40 \\
\hline W2 & 19.03 & 8.04 & 947 & 0.23 & -0.65 & 3.50 & 46.00 \\
\hline cubeW2 & 1.51 & 0.10 & 947 & -0.47 & -0.59 & 1.20 & 1.74 \\
\hline $\mathrm{K} 2$ & 1.02 & 0.12 & 947 & 3.14 & 33.25 & 0.69 & 2.43 \\
\hline $\mathrm{CI} 2$ & 0.13 & 0.01 & 947 & 0.95 & 1.12 & 0.10 & 0.19 \\
\hline L3 & 16.82 & 3.00 & 875 & -0.62 & -0.74 & 9.70 & 23.00 \\
\hline W3 & 48.30 & 21.96 & 876 & -0.11 & -0.81 & 5.50 & 113.50 \\
\hline cubeW3 & 1.72 & 0.14 & 876 & -0.83 & -0.37 & 1.28 & 1.98 \\
\hline K3 & 0.93 & 0.09 & 875 & 0.73 & 1.48 & 0.60 & 1.40 \\
\hline $\mathrm{CI} 3$ & 0.10 & 0.01 & 875 & 0.93 & -0.26 & 0.08 & 0.14 \\
\hline Number & 8.53 & 1.176 & 1001 & -1.22 & 5.21 & 1.00 & 12.00 \\
\hline asn(num) & 1.01 & 0.112 & 1001 & -0.64 & 5.25 & 0.29 & 1.57 \\
\hline contrast & 1.69 & 0.266 & 1001 & 1.13 & 1.77 & 1.17 & 2.94 \\
\hline asn(con) & 0.89 & 0.089 & 1001 & -0.10 & 0.02 & 0.62 & 1.18 \\
\hline
\end{tabular}

${ }^{\mathrm{a}} \mathrm{K}$, Fulton's condition factor $\left(\mathrm{g} . \mathrm{cm}^{-3}\right)$; L, total length $(\mathrm{cm})$; W, wet weight $(\mathrm{g})$; transformed traits: cubeW, cuberoot $\left(\right.$ wet weight) $\left(\mathrm{g}{ }^{-0.33}\right)$, CI, cubeW divided by total length. The suffixes 1, 2 and 3 refer to the measurement times. The alevins hatched on 10 February 2006 after approximately 616 degree days. The first measurement period was 30 August to 4 September 2006, the second measurement period was on 10-18 November 2006 and the third measurement period was on 24-28 May 2007. Number, number of parr marks at time 1, which was transformed before analysis 'asn(num)' using arcsin(sqrt(number parr marks/12)). Contrast, contrast of parr marks at time 1, which was transformed before analysis 'asn(con)' using $\arcsin (\operatorname{sqrt}(1 /$ contrast)).

were reared in a common environment. The pure Saint John's strain had significantly fewer parr marks than did the pure Mowi strain (two sample $t$-test, $P<0.00001)$. The Saint John's strain had a mean number of 5.9 (s.d.: 2.4, $n=29$ ) parr marks (Supplementary Figure 3a), whereas the Mowi strain had a mean number of 8.3 (s.d.: 1.1, $n=30$ ) parr marks (Supplementary Figure $3 b$ ). However, the difference in parr mark contrast between the two strains was not quite significant $(P=0.054)$. There were also differences in shape between the two strains. The head and tail were proportionately longer and the insertion of the dorsal fin and of the adipose fin was higher and more forward, and the pectoral fin was in a different shape for the pure Mowi strain than for the Saint John's strain (Supplementary Figure 3c).

All known Atlantic salmon linkage groups were represented in the QTL analysis, except for linkage group 20. However, when linkage group 20 was represented in a separate QTL analysis for Family A, which had been genotyped for 320 SNPs, it was not significantly associated with any growth, parr mark or morphometric traits (EG Boulding, unpublished data).

Linkage group affiliations for the SNP markers based on male meioses (Supplementary Appendix 2) were almost identical to those found in a more detailed linkage map for males from a Norwegian aquacultural strain of salmon (Moen et al., 2008). However, pseudolinkage relationships differed, in that more pseudolinkages were detected in the present data set. More specifically, pseudolinkage was observed between linkage groups 1 and 12, between 4 and 11, between 22 and 24 and among 19, 28 and 31. None of these pseudolinkages were observed conclusively in the Moen et al. (2008) map, perhaps because their map was constructed from 'pure-strain' Norwegian aquaculture salmon. This is in line with the hypothesis (reviewed by Danzmann et al., 2005) that pseudolinkage, the apparent linkage of non-linked chromosomes sometimes observed in male salmonids (for example, Wright et al., 1983), occurs more frequently in interstrain hybrids than in pure strain fish.

The results of the QTL analysis for the growth and condition traits are shown in Table 3. Highly significant QTLs for weight and condition at all three measurement periods were found on linkage groups AS9 and AS24. The QTL(s) on AS24 accounted from 26 to $43 \%$ of the phenotypic variance for all six traits suggesting that a major gene(s) was involved. Examination of the estimated gene effects showed that much of this was additive variance rather than dominance variance and would therefore respond to selection (Table 3 ). The most interesting finding, however, was that some of the QTLs that affected early parr growth were different than those that affected late parr growth. A QTL on linkage group AS3 was highly significant for growth until measurement period one but was not significant for growth until measurement periods two and three, whereas the reverse was true for a QTL on AS1. There were also QTLs for condition traits and growth to measurement period three on linkage groups AS18 and AS21 and a small QTL for growth to measurement period two on AS28 (Table 3).

Unexpectedly, parr mark number was determined by at least three QTLs on linkage groups AS18, AS19 and AS22 that collectively accounted for 32 per cent of the phenotypic variance (Table 4). A similar amount of the variance in parr mark contrast was accounted for by the two linkage groups: AS1 and AS24 with AS24 alone accounting for $25.6 \%$ of the variance. Examination of the magnitude of gene effects (Table 4) showed that much of this was additive variance rather than dominance variance and would therefore respond to selection. 
Table 3 Linkage groups containing QTLs significant for weight (W), and condition factor (K) for families A-D at measurement times 1, 2 or 3

\begin{tabular}{|c|c|c|c|c|c|c|c|c|}
\hline$L G^{\mathrm{a}}$ & Trait $^{\mathrm{b}}$ & $\operatorname{pos}^{\mathrm{c}}(\mathrm{cM})$ & $\mathrm{F}^{\mathrm{d}}$ & Mean $^{\mathrm{e}}$ & s.e. ${ }^{\mathrm{f}}$ & Additive & Dominance $^{\mathrm{h}}$ & $P E V^{\mathrm{i}}$ \\
\hline AS1 & cubeW2 & 0 & $9.35^{* *}$ & 1.529 & 0.00686 & -0.026 & 0.0188 & 8.7 \\
\hline AS1 & cubeW3 & 0 & $14.7^{* *}$ & 1.736 & 0.00989 & -0.047 & 0.0341 & 13.5 \\
\hline AS1 & CI2 & 0 & $10.2^{* *}$ & 0.124 & 0.00082 & 0.0033 & 0.0022 & 9.3 \\
\hline AS1 & $\mathrm{CI} 3$ & 0 & $17.1^{* *}$ & 0.104 & 0.00083 & 0.0045 & -0.0027 & 15.4 \\
\hline AS3 & cubeW1 & 0 & $8.63^{*}$ & 1.449 & 0.00560 & -0.017 & 0.0181 & 8.0 \\
\hline AS3 & CI1 & 0 & $9.80^{* * *}$ & 0.133 & 0.00076 & 0.0025 & -0.0026 & 9.0 \\
\hline AS9 & cubeW1 & 0 & $12.1^{* *}$ & 1.460 & 0.00554 & -0.0274 & 0.0047 & 11.2 \\
\hline AS9 & cubeW2 & 0 & $8.02^{*}$ & 1.536 & 0.00693 & -0.0276 & 0.0079 & 7.5 \\
\hline AS9 & cubeW3 & 0 & $12.4^{* *}$ & 1.750 & 0.01000 & -0.0499 & 0.0109 & 11.4 \\
\hline AS9 & CI1 & 0 & $9.72^{*}$ & 0.131 & 0.00076 & 0.0034 & -0.0008 & 9.0 \\
\hline AS9 & CI2 & 0 & $7.28^{*}$ & 0.123 & 0.00083 & 0.0032 & -0.0004 & 6.5 \\
\hline AS9 & CI3 & 0 & $6.75^{*}$ & 0.104 & 0.00085 & 0.0031 & -0.0010 & 6.2 \\
\hline AS18 & cubeW3 & 4 & $17.2^{* *}$ & 1.759 & 0.00994 & -0.056 & -0.0070 & 15.7 \\
\hline AS18 & CI1 & 3 & $7.21^{*}$ & 0.131 & 0.00077 & 0.0028 & 0.0004 & 7.0 \\
\hline AS18 & CI2 & 5 & $10.5^{* *}$ & 0.122 & 0.00082 & 0.0032 & 0.0014 & 9.6 \\
\hline AS18 & $\mathrm{CI} 3$ & 5 & $18.8^{* *}$ & 0.102 & 0.00083 & 0.0048 & 0.0007 & 16.7 \\
\hline AS21 & cubeW3 & 0 & $7.47^{*}$ & 1.763 & 0.01180 & -0.0529 & -0.011 & 7.0 \\
\hline AS21 & CI2 & 0 & $7.03^{*}$ & 0.121 & 0.00098 & 0.0037 & 0.0018 & 6.5 \\
\hline AS21 & $\mathrm{CI} 3$ & 0 & $7.24^{*}$ & 0.102 & 0.00100 & 0.0045 & 0.0007 & 6.6 \\
\hline AS22_24 & cubeW1 & 25 & $45.3^{* *}$ & 1.498 & 0.00676 & -0.0687 & -0.0288 & 38.7 \\
\hline AS22_24 & cubeW2 & 26 & $39.1^{* *}$ & 1.583 & 0.00815 & -0.0625 & -0.0499 & 33.9 \\
\hline AS22_24 & cubeW3 & 28 & $29.5^{* *}$ & 1.795 & 0.01112 & -0.0623 & -0.0648 & 26.1 \\
\hline AS22_24 & CI1 & 25 & $50.2^{* *}$ & 0.125 & 0.00092 & 0.0084 & 0.0062 & 42.6 \\
\hline AS22_24 & $\mathrm{CI} 2$ & 26 & $41.6^{* *}$ & 0.117 & 0.00097 & 0.0071 & 0.0068 & 35.7 \\
\hline AS22_24 & $\mathrm{CI} 3$ & 28 & $28.9^{* *}$ & 0.100 & 0.00094 & 0.0046 & 0.0060 & 25.6 \\
\hline AS28 & cubeW2 & 0 & $7.58^{*}$ & 1.537 & 0.00727 & -0.0283 & 0.0064 & 7.1 \\
\hline AS28 & $\mathrm{CI} 3$ & 1 & $8.40^{*}$ & 0.104 & 0.00089 & 0.0031 & 0.0022 & 7.6 \\
\hline
\end{tabular}

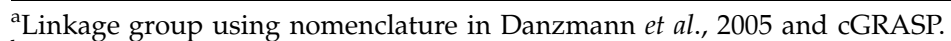

${ }^{\text {b }}$ See Table 1 for description of traits. Transformed traits: cubeW, cuberoot(wet weight) $\left(\mathrm{g}^{-0.33}\right)$, CI, cubeW divided by total length. The suffixes 1,2 and 3 refer to the measurement times.

'Position on linkage group (map made from meioses in trans-Atlantic hybrid males, see Supplementary Appendix 2).

${ }^{\mathrm{d}} F$-test with experimentwise criterion of significance $\left.{ }^{*} P<0.05,{ }^{* *} P<0.01\right)$ using permutation test in QTL Express for complete analysis with all four backcross families carried out separately for each trait.

e Transformed mean of trait.

${ }^{\text {f}}$ Standard error of the trait mean, which was very similar to standard errors of additive and dominance gene effects.

${ }^{\mathrm{g}}$ Additive gene effect on mean. If the allele substitution effect is positive then the effect of the homozygous QTL genotype is larger than the effect of the heterozygous genotype.

${ }^{\mathrm{h}}$ Dominance gene effect on mean. If the allele substitution effect is positive then the effect of the homozygous QTL genotype is larger than the effect of the heterozygous genotype.

${ }^{\mathrm{i}}$ Proportion of phenotypic variance accounted for by QTL.

There were also significant QTLs on 15 different linkage groups for the 30 aligned landmark coordinates that we used to quantify shape (Table 5; Supplementary Figure 4). A highly significant QTL on AS1 accounted for $26.7 \%$ of the variance in the pectoral fin landmark, Y12. An especially interesting case was landmark 3, which had an $\mathrm{x}$ coordinate position significantly associated with linkage group AS5 and a y coordinate position significantly associated with AS24. Another interesting case was that AS1 had a positive additive effect on the $y$ coordinate for landmark 2, whereas AS24 had a negative additive effect. AS24 notably was associated with the $x$ coordinate for 11 traits $(X 1, X 2, X 4, X 5, X 6, X 7, X 8$, $\mathrm{X} 10, \mathrm{X} 11, \mathrm{X} 13$ and $\mathrm{X} 15)$ and two $\mathrm{y}$ coordinates (Y2 and Y3). Interestingly, five of these $x$ coordinates experienced positive additive gene effects, whereas six experienced negative additive effects (Table 5). The associations with linkage group AS24 explained more than $30 \%$ of the variance for each of three morphometric traits (X1, X10 and X11) suggesting that a major gene(s) was involved.

Supplementary Figure 5shows the functional significance of how these QTLs associated with major loci affected body shape. When the marker allele substitution at linkage group AS24 resulted in a homozygous genotype, the jaw of the fish became shorter, the body depth became shallower and the pectoral and the caudal fins became longer and the pectoral, pelvic and dorsal fins changed their attachment position (Supplementary Figure 5a). Similarly, when the marker allele substitution at linkage group AS1 resulted in a homozygous genotype, the fish became deeper bodied behind the head and the lower anterior insertion of the pectoral fin became lower (Supplementary Figure $5 b$ ).

The effect of sex on the QTL associations could only be assessed for family B. In family B, the SNP marker Ssa0182ECIG on linkage group AS1 had a CG genotype in $80 \%$ of the 60 phenotypic females and a GG genotype in $76 \%$ of the 61 phenotypic males $\left(\chi^{2}=39.3, \mathrm{df}=1\right.$, $P<0.0001)$. This suggests that at the $\mathrm{G}$ allele from the sire (family B: sire GC, dam CC) was linked to the sexdetermining locus on AS1. A factorial ANOVA ( $\mathrm{df}=1$, 117) for W3 was not significant for phenotypic sex $(P=0.724)$ or SNP genotype at Ssa0182ECIG $(P=0.082)$ but their interaction was suggestive $(P=0.056)$. Similarly, the ANOVA $(\mathrm{df}=1,117)$ for $\mathrm{CI} 3$ was not significant for sex $(P=0.699)$ or genotype $(P=0.088)$ but their interaction was suggestive $(P=0.069)$. 
Table 4 Linkage groups containing QTLs significant for parr mark number (number) or parr mark contrast (contrast) at measurement time 1

\begin{tabular}{|c|c|c|c|c|c|c|c|c|}
\hline$L G^{\mathrm{a}}$ & Trait $^{\mathrm{b}}$ & $\operatorname{pos}^{\mathrm{c}}(\mathrm{cM})$ & $F^{d}$ & $\operatorname{Mean}^{\mathrm{e}}$ & s.e. $^{\mathrm{f}}$ & Additive $\mathrm{g}$ & Dominance $^{\mathrm{h}}$ & $P E V^{\mathrm{i}}$ \\
\hline AS1 & asn(contrast) & 0 & $8.17^{*}$ & 0.886 & 0.00572 & -0.0232 & 0.0046 & 6.6 \\
\hline AS18 & asn(num) & 4 & $8.54^{*}$ & 1.006 & 0.00728 & -0.0291 & 0.0133 & 6.8 \\
\hline AS19_31 & asn(num) & 0 & $9.7^{*}$ & 1.007 & 0.00746 & -0.0317 & 0.0135 & 7.8 \\
\hline AS22_24 & asn(num) & 1 & $13.03^{* *}$ & 1.018 & 0.00717 & -0.0365 & 0.0028 & 10.3 \\
\hline AS22_24 & asn(contrast) & 30 & $33.49^{* *}$ & 0.911 & 0.00602 & -0.0278 & -0.0326 & 25.6 \\
\hline
\end{tabular}

Note that the position on the pseudolinkage group 22_24 for parr mark number is nearest to AS22, whereas that for parr mark contrast is nearest to AS24 (Supplementary Appendix 1).

aLinkage group using nomenclature in Danzmann et al., 2005 and cGRASP.

${ }^{\mathrm{b}}$ See Table 1 for description of traits.

${ }^{c}$ Position on linkage group (map made from meioses in trans-Atlantic hybrid males, see Supplementary Appendix 2).

${ }^{\mathrm{d}} F$-test with experiment-wise criterion of significance $\left({ }^{*} P<0.05,{ }^{* *} P<0.01\right)$ using permutation test in QTL Express for complete analysis with all four backcross families carried out separately for each trait.

'Transformed mean of trait.

${ }^{\mathrm{f}} \mathrm{S}$ tandard error of the trait mean, which was very similar to standard errors of additive and dominance gene effects.

${ }^{g}$ Additive gene effect. If the allele substitution effect is positive then the effect of the homozygous QTL genotype is larger than the effect of the heterozygous genotype.

${ }^{h}$ Dominance gene effect. If the allele substitution effect is positive then the effect of the homozygous QTL genotype is larger than the effect of the heterozygous genotype.

${ }^{\mathrm{i}}$ Proportion of phenotypic variance accounted for by QTL.

\section{Discussion}

The most novel part of our study is the detection of three major QTLs that affected the number of parr marks in juvenile Atlantic salmon and two major QTLs that affected the contrast between the skin and the parr marks. Linkage group AS22 contained a large QTL for parr mark number, whereas AS24 contained a large QTL for parr mark contrast. This is interesting because the two linkage groups AS22 and AS24 are known to be homologues (Danzmann et al., 2005) and would be expected to contain duplicated genes from the tetraploidation event. Our linkage map includes the pseudolinkage between AS22 and AS24 and the QTL positions showed that parr mark number was on AS22 and parr mark contrast was on AS24. This suggests that these two traits can evolve independently. Further evidence that parr mark number has a partial genetic basis was obtained when we reared the two paternal grandparent purebred populations from different continents in a common environment and observed significantly fewer parr marks in the St John's strain than in the Mowi strain.

It is exciting that we have detected major QTLs affecting parr mark number and contrast in our backcross families because both traits show genetic variation among wild Atlantic salmon populations. We previously found that five parr populations from different New Brunswick Rivers showed significant differences in the number and contrast of the parr marks even when reared in a common environment at Mactaquac Biodiversity Centre (M Culling and EG Boulding, unpublished data). There was also a tendency for an increased number of parr marks to be positively correlated with increased contrast (M Culling and EG Boulding, unpublished data). However, as these two traits map to different linkage groups, this phenotypic correlation may reflect convergent selective pressures rather than shared genetic loci. Birds preying on parr in streams with a more heterogeneous gravel bottom might select for more and darker parr marks. Conversely, birds preying on parr in streams with a simple homogenous mud bottom might select for fewer parr marks with less contrast so that the skin pigmentation is evenly brown (Mezzera et al., 1997). Genetic adaptation may occur because substrate type and background coloration varies considerably among streams and juvenile salmon have only a limited ability to acclimate (Donnelly and Whoriskey, 1993). Atlantic salmon parr from stream channels with a brown background experienced relatively higher rates of predation from hooded mergansers (Lophodytes cucullatus) in both brown and tan experimental stream channels than did parr from channels with a tan background (Donnelly and Whoriskey, 1993). This supports the hypothesis that there is strong diversifying selection for skin patterns and colouration of parr that matches the substrate of their natal stream.

What is remarkable about our study was the large number of highly significant QTLs that we found for traits of interest to aquaculture, such as growth and condition factor. We attribute this to our creation of transAtlantic backcrosses that are segregating for European alleles and North American alleles at the SNP marker loci and likely also for many QTLs themselves. The paternal granddam for these particular backcrosses was from the Mowi A/S. company's aquaculture strain, which has presumably been heavily selected for growth rate, since it was first farmed in 1969 (Gjedrem et al., 1991). Similarly, the Canadian Saint John's strain has also experienced three or four generations of selection for faster growth (Quinton et al., 2005). Such strong selection within a strain is likely to have fixed alleles at major loci affecting growth and condition factor by affecting feeding behaviour and growth hormone levels (Ferguson et al., 2007). Yet we detected significant additive genetic variance for both growth and condition factor. We postulate that our trans-Atlantic backcross between two subspecies may have restored segregation at major loci affecting growth rate, which allowed us to detect them. This would be possible if artificial selection within each strain had fixed different loci in the Saint John's strain than in the Mowi strain.

We did not find growth in QTLs on the same linkage groups as have been previously reported for families of the pure Saint John's aquacultural strain. Reid et al. 
Table 5 Linkage groups containing QTLs significant for 15 morphometric landmark coordinates at measurement time 1

\begin{tabular}{|c|c|c|c|c|c|c|c|c|}
\hline$L G^{\mathrm{a}}$ & Trait $^{\mathrm{b}}$ & $\operatorname{pos}^{\mathrm{c}}(\mathrm{cM})$ & $F^{\mathrm{d}}$ & $\operatorname{Mean}^{\mathrm{e}}$ & s.e. ${ }^{\mathrm{f}}$ & Additives & Domin $^{\mathrm{h}}$ & $P E V^{i}$ \\
\hline AS1 & Y2 & 0 & $12.4^{* *}$ & 0.0340 & 0.000218 & 0.0011 & -0.0003 & 10.8 \\
\hline AS1 & X8 & 1 & $9.8^{*}$ & 0.2888 & 0.000274 & -0.0006 & 0.0011 & 6.9 \\
\hline AS1 & X9 & 1 & $11.9^{* *}$ & 0.1540 & 0.000321 & -0.0014 & -0.0005 & 8.3 \\
\hline AS1 & X10 & 0 & $11.0^{* *}$ & 0.0138 & 0.000343 & 0.0013 & -0.0011 & 8.8 \\
\hline AS1 & X12 & 0 & $8.81^{*}$ & -0.1943 & 0.000203 & -0.0006 & 0.0007 & 8.4 \\
\hline AS1 & Y12 & 0 & $34.1^{* *}$ & -0.0438 & 0.000157 & -0.0013 & 0.0004 & 26.7 \\
\hline AS1 & X13 & 1 & $10.8^{* *}$ & -0.2153 & 0.000163 & -0.0007 & 0.0004 & 12.7 \\
\hline AS2 & Y12 & 0 & $8.05^{*}$ & -0.0445 & 0.000172 & 0.0008 & -0.0002 & 6.7 \\
\hline AS3 & $\mathrm{X} 3$ & 1 & $8.46^{*}$ & -0.0455 & 0.000392 & 0.0015 & -0.0008 & 5.8 \\
\hline AS3 & X15 & 0 & $7.11^{*}$ & -0.3206 & 0.000248 & -0.0008 & 0.0006 & 5.9 \\
\hline AS4 & Y4 & 1 & $7.09^{*}$ & 0.0537 & 0.000237 & 0.0013 & -0.0006 & 6.1 \\
\hline AS4 & Y11 & 1 & $9.14^{*}$ & -0.0288 & 0.000650 & -0.0043 & 0.0024 & 7.3 \\
\hline AS5 & X3 & 0 & $9.03^{*}$ & -0.0449 & 0.000416 & -0.0015 & 0.0009 & 7.0 \\
\hline AS7 & Y5 & 0 & $9.27^{*}$ & 0.0355 & 0.000149 & 0.0006 & -0.0001 & 7.8 \\
\hline AS7 & Y10 & 0 & $10.3^{*}$ & -0.0660 & 0.000269 & -0.0012 & 0.0000 & 9.5 \\
\hline AS7 & Y12 & 0 & $11.8^{*}$ & -0.0439 & 0.000160 & -0.0008 & 0.0001 & 13.3 \\
\hline AS9 & X3 & 0 & $13.1^{* *}$ & -0.0463 & 0.000389 & 0.0019 & 0.0003 & 9.3 \\
\hline AS9 & Y4 & 0 & $9.84^{* *}$ & 0.0544 & 0.000241 & -0.0010 & 0.0005 & 9.2 \\
\hline AS9 & X6 & 0 & $11.5^{* *}$ & 0.3513 & 0.000269 & -0.0012 & -0.0003 & 9.8 \\
\hline AS10 & X14 & 3 & $11.1^{* *}$ & -0.2914 & 0.000288 & -0.0013 & -0.0002 & 10.8 \\
\hline AS11 & $\mathrm{X} 1$ & 0 & $8.93^{*}$ & -0.3600 & 0.000340 & -0.0010 & -0.0009 & 7.4 \\
\hline AS11 & Y3 & 0 & $14.0^{* *}$ & 0.0904 & 0.000297 & -0.0015 & 0.0006 & 11.7 \\
\hline AS11 & X9 & 0 & $13.4^{* *}$ & 0.1520 & 0.000321 & 0.0014 & 0.0006 & 10.0 \\
\hline AS11 & Y12 & 0 & $9.13^{*}$ & -0.0444 & 0.000161 & 0.0007 & -0.0003 & 6.7 \\
\hline AS11 & X15 & 2 & $8.80^{*}$ & -0.3200 & 0.000246 & -0.0006 & -0.0008 & 5.9 \\
\hline AS12 & X10 & 0 & $10.1^{*}$ & 0.0142 & 0.000343 & -0.0014 & 0.0008 & 8.8 \\
\hline AS12 & X12 & 1 & $12.3^{*}$ & -0.1943 & 0.000202 & 0.0008 & -0.0007 & 8.4 \\
\hline AS13 & X13 & 0 & $8.60^{*}$ & -0.2151 & 0.000164 & -0.0006 & -0.0001 & 12.7 \\
\hline AS16 & Y10 & 2 & $8.06^{*}$ & -0.0662 & 0.000269 & -0.0011 & 0.0002 & 7.1 \\
\hline AS18 & $\mathrm{X} 1$ & 2 & $7.87^{*}$ & -0.3604 & 0.000347 & -0.0014 & 0.0002 & 7.4 \\
\hline AS18 & X6 & 6 & $8.22^{*}$ & 0.3510 & 0.000269 & -0.0011 & 0.0001 & 7.3 \\
\hline AS18 & X10 & 7 & $21.6^{* *}$ & 0.0127 & 0.000343 & 0.0021 & 0.0005 & 17.6 \\
\hline AS18 & X14 & 5 & $8.37^{*}$ & -0.2920 & 0.000283 & -0.0011 & 0.0006 & 8.6 \\
\hline AS22_24 & X1 & 23 & $43.0^{* *}$ & -0.3575 & 0.000459 & 0.0045 & -0.0022 & 32.7 \\
\hline AS22_24 & $\mathrm{X} 2$ & 21 & $13.8^{* *}$ & -0.2005 & 0.000624 & 0.0035 & 0.0019 & 11.9 \\
\hline AS22_24 & Y2 & 30 & $16.6^{* *}$ & 0.0337 & 0.000234 & -0.0005 & 0.0018 & 14.4 \\
\hline AS22_24 & Y3 & 23 & $10.7^{*}$ & 0.0890 & 0.000415 & -0.0004 & 0.0022 & 7.8 \\
\hline AS22_24 & $\mathrm{X} 4$ & 24 & $20.4^{* *}$ & 0.2056 & 0.000410 & -0.0023 & -0.0020 & 16.1 \\
\hline AS22_24 & X5 & 25 & $28.9^{* *}$ & 0.2976 & 0.000410 & -0.0030 & -0.0019 & 22.8 \\
\hline AS22_24 & X6 & 22 & $13.2^{* *}$ & 0.3522 & 0.000384 & -0.0019 & -0.0014 & 9.8 \\
\hline AS22_24 & X7 & 27 & $18.4^{* *}$ & 0.4035 & 0.000379 & 0.0019 & 0.0016 & 13.4 \\
\hline AS22_24 & X8 & 22 & $20.2^{* *}$ & 0.2912 & 0.000394 & -0.0018 & -0.0024 & 16.0 \\
\hline AS22_24 & X10 & 22 & $44.6^{* *}$ & 0.0102 & 0.000480 & 0.0029 & 0.0045 & 33.7 \\
\hline AS22_24 & X11 & 23 & $38.5^{* *}$ & -0.0919 & 0.001079 & 0.0089 & 0.0068 & 29.1 \\
\hline AS22_24 & X13 & 24 & $20.5^{* *}$ & -0.2144 & 0.000217 & -0.0006 & -0.0015 & 19.0 \\
\hline AS22_24 & X15 & 21 & $29.7^{* *}$ & -0.3186 & 0.000357 & -0.0030 & -0.0012 & 20.6 \\
\hline AS28 & X11 & 0 & $13.4^{* *}$ & -0.0848 & 0.000844 & 0.0039 & -0.0022 & 10.6 \\
\hline
\end{tabular}

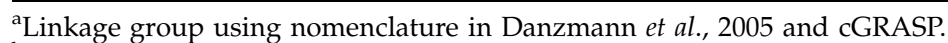

${ }^{\mathrm{b}}$ See text and Supplementary Figure 1 for landmark positions.

${ }^{c}$ Position on linkage group (map made from meioses in trans-Atlantic hybrid males, see Supplementary Appendix 2).

${ }^{\mathrm{d}} F$-test with experiment-wise criterion of significance $\left({ }^{*} P<0.05,{ }^{* *} P<0.01\right)$ using permutation test in QTL Express for complete analysis with all four backcross families carried out separately for each trait.

${ }^{\text {e}}$ Transformed mean of trait.

${ }^{\mathrm{f}}$ Standard error of the trait mean, which was very similar to standard errors of additive and dominance mean effects.

${ }^{\mathrm{g}}$ Additive gene effect. If the allele substitution effect is positive then the effect of the homozygous QTL genotype is larger than the effect of the heterozygous genotype.

${ }^{\mathrm{h}}$ Dominance gene effect. If the allele substitution effect is positive then the effect of the homozygous QTL genotype is larger than the effect of the heterozygous genotype.

${ }^{\mathrm{i}}$ Proportion of phenotypic variance accounted for by QTL.

(2005) found significant QTLs for body weight on AS8 and AS11. This may have been because, even at measurement period 3, our fish were less than half the weight of his fish, which averaged $126 \mathrm{~g}$. However, we did find significant QTLs for condition factor on two of the four linkage groups that he reported, AS2 and AS11. QTLs can only be detected when both the marker locus and the QTL locus have alleles that are segregating within a particular family. For example, none of the large QTLs that we detected on linkage group AS24 were found in family A because none of the AS24 SNP markers were polymorphic for that family.

Ours is the second study to find QTLs for body shape in fishes using techniques from geometric morphometrics (see Albert et al., 2008) and the first with salmonids. We observed that the jaw of the parr became 
shorter, the body depth becomes shallower and the pectoral fin becomes longer in association with a particular allele being inherited at a particular SNP on linkage group AS24. Similarly, pectoral fin position, caudal peduncle position changed in association with a particular allele being inherited at a particular SNP on linkage group AS1. Several of these shape changes were in the same direction as seen in morphing from a Saint John's strain to a pure Mowi strain, wherein the head and tail became proportionately longer, the insertion of the dorsal fin and of the adipose fin became higher and more forward and the shape of the pectoral fin changed. Further evidence that segregation of alleles for shape occurred in our backcross families was obtained when we reared the two paternal grandparent purebred populations from different continents in a common environment and observed persistent differences in $x$ and $y$ coordinates of the 15 landmarks. Early parr from seven New Brunswick populations reared in a common environment at Mactaquac Biodiversity Centre showed genetic variation in landmarks affecting jaw length, pectoral fin length and fin position (M Culling and EG Boulding, unpublished data), which corresponds with variation, which we observed, segregating in our backcrosses. Our trans-Atlantic cross was between two aquacultural strains from different continents that allowed us to detect a large number of highly significant QTLs for body and fin shape. This suggests that morphometric differences among populations in response to local adaptation to different streams are also likely to have a genetic component.

Several previous studies have attempted to provide evidence that adaptive differences in body form and fin size among populations were genetic, by showing that they persisted when salmon were reared in a common environment. Genetic divergence in head morphology of Atlantic salmon has been postulated to occur at small geographical scales such as between different tributaries in a river system (Riddell et al., 1981), as well as at large geographical scales such as across continents (Claytor et al., 1991). Trout populations reared in two different common environments showed some phenotypic plasticity in shape but many morphological differences persisted; fin length was longest in populations from faster streams and mouth size was maximum in populations that were piscivorous (Keeley et al., 2007). Long pectoral fins are used as a station-holding stabilizing device or reverse hydrofoil by parr populations whose feeding territories are in streams with high flow velocities; the pelvic fin can also be used to grip the bottom when gravel is present (Arnold et al., 1991). Early parr from the Norwegian AquaGen strain are adapted to low flow velocities and had smaller pectoral and ventral fins as well as smaller heads and smaller eye diameters than parr from four wild Norwegian populations (Solem et al., 2006). An increase in the surface area of the pectoral fins has been shown to increase endurance in sticklebacks by increasing swimming efficiency (A Dalziel, personal communication).

We found QTLs for body depth, which is also known to affect swimming efficiency. Comparative studies suggest that a streamlined body form is a genetic adaptation to prolonged swimming in streams with high flow velocities (Riddell et al., 1981; Riddell and Leggett, 1981), whereas a deeper body is adaptive for burst swimming (Bisson et al., 1988). Atlantic salmon parr populations inhabiting fast-flowing streams or in the head waters of large rivers have shallower bodies and smaller median fins than those inhabiting slower-flowing streams or living near the coast (Nicieza, 1995). Further, parr populations that maintain feeding territories in streams for prolonged periods tend to have deeper bodies than populations that spend only a short time in freshwater before migrating to lakes or oceans (Nicieza, 1995).

Several linkage groups were notable in having large effects on more than one trait. Linkage group AS1 contained QTL(s) for pectoral fin position, caudal peduncle position, late parr growth and condition index. Linkage group AS24 contained a large QTL(s) that was associated with the $x$ coordinates of 11 different morphometric landmarks, and parr mark contrast, as well as weight and condition at all three measurement periods. Further high-resolution QTL study is needed before we knowing whether these associations with all these different traits are all caused by the same gene or are caused by multiple genes on the same linkage group or a homologous linkage group. Associations caused by different genes could appear to be caused by a single large QTL because of very low recombination (Noor et al., 2001), or pseudolinkage, in the hybrid sires used in our experimental crosses.

Among the genes that linkage group AS1 is known to contain the homeotic gene loci HoxA2bi and Hox A11bi (Moghadam et al., 2005) as well as the sex locus (Artieri et al., 2006). The significant interaction in the factorial ANOVA for W3 and for CI3 suggests that the effect of the QTL allele that was inherited from the trans-Atlantic hybrid sire may differ for each sex. Many large adult body shape QTLs in an F2 cross between two divergent stickleback populations mapped to the sex-determining region (Albert et al., 2008).

Among the genes that AS24 is known to contain (Moghadam et al., 2007b) are myogenic growth factor 6 (mgf) and insulin-like growth factor 1. Insulin-like growth factor 1 is a particularly interesting candidate gene because its documented effect on the expression of pattern-forming proteins would permit one linkage group AS24 to affect the coordinates of 13 different landmarks. Insulin-like growth factor signalling is required for early dorsoanterior development of the zebrafish embryo and is known to affect the expression of bone morphogenetic protein 2b (BMP2b), which is important in pattern formation (Eivers et al., 2004). Expression patterns of a closely related protein, BMP4, have been shown to affect lever ratios in the jaw formation of cichlid fishes and to segregate with a QTL that accounted for a large amount of the variation in an F2 cross between two species with different jaw morphologies (Albertson et al., 2005).

Future study will involve fine mapping the QTLs that we have detected to a particular chromosome location, which will allow us to identify alleles at QTNs that characterize salmon populations inhabiting different environments. We have already used outlier analysis of these 320 SNP loci that were genotyped for seven different Bay of Fundy rivers to identify some chromosomal regions under selection for different optima in different rivers ( $\mathrm{M}$ Culling and EG Boulding, unpublished data). Mapping these outlier loci might most 
efficiently be carried out using a combined linkage disequilibrium/linkage (LDLA) design (Meuwissen et al., 2002). Alternatively, the very large family sizes that are possible in salmonids for the F2 generation might facilitate fine scale mapping of the QTLs for ecologically important traits that we have detected here. Ron and Weller (2007) argue that QTNs can be validated without transgenetics by using fine-scale LDLA mapping, positional cloning of the QTL region and DNA sequencing of candidate genes, then applying their formula to calculate 'probability of concordance by chance'. This suggests that it will be possible to locate QTNs responsible for adaptive trait differences among Atlantic salmon populations from different rivers by measuring these traits on trans-Atlantic F2 crosses that had been genotyped for a large number of SNP markers. Encouragingly, identification of a QTN has already been achieved for a single locus trait in stickleback fishes, where parallel evolution of a reduced pelvic girdle in freshwater forms has been linked to a repeated fixation of ectodysplasin alleles (Colosimo et al., 2005).

\section{Acknowledgements}

We thank W Young-Lai of DFO for doing the crosses, pittagging and rearing the fish; A Roseth, K Sundsaasen, $\mathrm{H}$ Munck and $M$ Baranski for carrying out the SNP genotyping and $\mathrm{H}$ Freamo, $\mathrm{M}$ Hansen and $\mathrm{H}$ Henriksen for assistance with DNA isolation. We also thank $M$ Gjerstad of Photofisk for suggesting how to measure parr mark contrast, TK Hay for database programming and D Morgan and K Patterson for finding some key references. Funding was from an NSERC (Canada) Strategic Project grant to EGB, I Fleming and P Schulte with assistance from CIGENE (to SL), AKVAFORSK (to TM), DFO Canada (to BG), the Atlantic Salmon Federation Cooke Aquaculture. The production of the trans-Atlantic crosses was made possible through an Aquaculture Collaborative Research and Development Grant MG-02-04-009 to BG and partners Dover Hatchery Ltd (PEI) and Stolt Seafarm Ltd (NB, BC).

\section{References}

Albert AYK, Sawaya S, Vines TH, Knecht AK, Miller CT, Summers BR et al. (2008). The genetics of adaptive shape shift in stickleback: pleiotropy and effect size. Evolution 62: 76-85.

Albertson RC, Streelman JT, Kocher TD, Yelick PC (2005). Integration and evolution of the cichlid mandible: the molecular basis of alternate feeding strategies. Proc Natl Acad Sci 102: 16287-16292.

Allendorf FW, Thorgaard GH (1984). Tetraploidy and the evolution of salmonid fishes. In: Turner BJ (ed). The Evolutionary Genetics of Salmonid Fishes. Plenum Press: New York, pp 1-53.

Arnold GP, Webb PW, Holford BH (1991). The role of the pectoral fins in station-holding of Atlantic salmon parr (Salmo salar). J Exp Biol 156: 625-629.

Artieri CG, Mitchell LA, Ng SHS, Parisotto SE, Danzmann RG, Hoyheim B et al. (2006). Identification of the sex-determining locus of Atlantic salmon (Salmo salar) on chromosome 2. Cytogenet Genome Res 112: 152-159.

Bisson P, Sullivan K, Nielsen JL (1988). Channel hydraulics, habitat use, and body form of juvenile coho salmon, steelhead, and cutthroat trout in streams. Trans Am Fish Soc 117: $262-273$.
Claytor RR, MacCrimmon HR (1988). Morphometric and meristic variability among North American Atlantic salmon (Salmo salar). Can J Zool 66: 310-317.

Claytor RR, MacCrimmon HR, Gots BL (1991). Continental and ecological variance components of European and North American Atlantic salmon (Salmo salar) phenotypes. Biol J Lin Soc 44: 203-229.

Colosimo PF, Hosemann KE, Balabhadra S, Villarreal Jr G, Dickson M, Grimwood J et al. (2005). Widespread parallel evolution in sticklebacks by repeated fixation of ectodysplasin alleles. Science 307: 1928-1933.

Colosimo PF, Peichel CL, Nereng K, Blackman BK, Shapiro MD, Schluter D et al. (2004). The genetic architecture of parallel armor plate reduction in threespine sticklebacks. PLoS Biol 2: 635-641.

Danzmann RG, Cairney M, Davidson WS, Ferguson MM, Gharbi K, Guyomard R et al. (2005). A comparative analysis of the rainbow trout genome with two other species of fish (Arctic charr and Atlantic salmon) within the tetraploid derivative Salmonidae family (subfamily: Salmoninae). Genome 48: 1037-1051.

Donnelly WA, Dill LM (1984). Evidence for crypsis in coho salmon Oncorhynchus kisutch (Walbaum), parr: substrate colour preference and achromatic reflectance. J Fish Biol 25: 183-195.

Donnelly WA, Whoriskey FG (1993). Transplantation of Atlantic salmon (Salmo salar) and crypsis breakdown. In: RJ Gibson, RE Cutting (eds). Can Spec Publ Fish Aquat Sci. Production of juvenile Atlantic salmon, Salmo salar, in natural waters, vol. 118. Ottawa, Canada, pp 25-34.

Eivers E, McCarthy K, Glynn C, Nolan CM, Byrnes L (2004). Insulin-like growth factor (IGF) signalling is required for early dorso-anterior development of the zebrafish embryo. Int J Dev Biol 48: 1131-1140.

Ferguson A, Fleming IA, Hindar K, Skaala $\varnothing$, McGinnity P, Cross Tet al. (2007). Chapter 12. Farm escapes. In: Verspoor E, Stradmeyer L, Nielsen J (eds). The Atlantic Salmon: Genetics, Conservation and Management. Blackwell: London, pp 357-398.

Garcia de Leaniz C, Fleming IA, Einum S, Verspoor E, Jordan WC, Consuegra $S$ et al. (2007). A critical review of adaptive genetic variation in Atlantic salmon: implications for conservation. Biol Rev Camb Philos Soc 82: 173-211.

Gilbey J, Verspoor E, McLay A, Houlihan D (2004). A microsatellite linkage map for Atlantic salmon (Salmo salar). Animal Genet 35: 98-105.

Gjedrem T, Gjøen HM, Gjerde B (1991). Genetic origin of Norwegian farmed Atlantic salmon. Aquaculture 98: 41-50.

Hayes B, Gjuvsland A, Omholt S (2006). Power of QTL mapping experiments in commercial Atlantic salmon populations, exploiting linkage and linkage disequilibrium and effect of limited recombination in males. Heredity 97: 19-26.

Hayes B, Lærdahl JK, Lien S, Moen T, Berg P, Hindar K et al. (2007). An extensive resource of single nucleotide polymorphism markers associated with Atlantic salmon (Salmo salar) expressed sequences. Aquaculture 265: 82-90.

Keeley ER, Parkinson EA, Taylor EB (2007). The origin of ecotypic variation in rainbow trout: a test of environmental vs genetically based differences in morphology. J Evol Biol 20: 725-736.

King TL, Verspoor E, Spidle AP, Gross R, Phillips RB, Koljonen M-L et al. (2007). Chapter 5. Biodiversity and population structure. In: Verspoor E, Stradmeyer L, Nielsen J (eds). The Atlantic Salmon: Genetics, Conservation and Management. Blackwell: London, pp 117-166.

Koljonen M-L, King TL, Nielsen EE (2007). Chapter 9. Genetic identification of individuals and populations. In: Verspoor E, Stradmeyer L, Nielsen J (eds). The Atlantic Salmon: Genetics, Conservation and Management. Blackwell: London, pp 270-298. 
Kudo H, Inoguchi N, Kijima A (2002). Estimation of the heritability of parr mark numbers by correlation between masou trout (Oncorhynchus masou) parents and offspring. Japanese J Fish Genet Breed Sci 32: 11-18 (In Japanese).

Lynch M, Walsh B (1998). Genetics and Analysis of Quantitative Traits. Sinauer Assoc Inc.: Sunderland, MA, 980pp.

Meuwissen THE, Karlsen A, Lien S, Olsaker I, Goddard ME (2002). Fine mapping of a quantitative trait locus for twinning rate using combined linkage and linkage disequilibrium mapping. Genetics 161: 373-379.

Mezzera M, Largiader CR, Scholl A (1997). Discrimination of native and introduced brown trout in River Doubs (Rhone drainage) by number and shape of parr marks. J Fish Biol 50: 672-677.

Moen T, Hayes B, Baranski M, Berg PR, Kjøglum S, Koop BF et al. (2008). A linkage map of the Atlantic salmon (Salmo salar) based on EST-derived SNP markers. BMC Genomics 9: 223.

Moen T, Hoyheim B, Munck H, Gomez-Raya L (2004). A linkage map of Atlantic salmon (Salmo salar) reveals an uncommonly large difference in recombination rate between the sexes. Anim Genet 35: 81-92.

Moghadam HK, Ferguson MM, Danzmann RG (2005). Evolution of Hox clusters in salmonidae: a comparative analysis between Atlantic salmon (Salmo salar) and rainbow trout (Oncorhynchus mykiss). J Mol Evol 61: 636-649.

Moghadam HK, Ferguson MM, Rexroad III CE, Coulibaly I, Danzmann RG (2007b). Genomic organization of the igf1, igf2, myf5, myf6 and grf/pacap genes across Salmoninae genera. Anim Genet 38: 527-532.

Moghadam HK, Poissant J, Fotherby H, Haidle L, Ferguson MM, Danzmann RG (2007a). Quantitative trait loci for body weight, condition factor and age at sexual maturation in Arctic charr (Salvelinus alpinus): comparative analysis with rainbow trout (Oncorhynchus mykiss) and Atlantic salmon (Salmo salar). Mol Genet Genomics 277: 647-661.

Nereng KS, Ohgi KA, Cole BL, Colosimo PF, Buerkle CA, Schluter D et al. (2001). The genetic architecture of divergence between threespine stickleback species. Nature 414: 901-905.

$\mathrm{Ng}$ SHS, Artieri CG, Bosdet IE, Chiu R, Danzmann RG, Davidson WS et al. (2005). A physical map of the Atlantic salmon genome. Genomics 86: 396-404.

Nicieza AG (1995). Morphological variation between geographically disjunct populations of Atlantic salmon: the effects of ontogeny and habitat shift. Functional Ecol 9: 448-456.

Noor MAF, Cunningham AL, Larkin JC (2001). Consequences of recombination rate variation on quantitative trait locus mapping studies: simulations based on the Drosophila melanogaster genome. Genetics 159: 581-588.

Pakkasmaa S, Piironen J (2001). Water velocity shapes juvenile salmonids. Evol Ecol 14: 721-730.

Quinton CD, McMillan I, Glebe B (2005). Development of an Atlantic salmon (Salmo salar) genetic improvement program: genetic parameters of harvest body weight and carcass quality traits estimated with animal models. Aquaculture 247: 211-217.

Reid DP, Szanto A, Glebe B, Danzmann RG, Ferguson MM (2005). QTL for body weight and condition factor in Atlantic salmon (Salmo salar): comparative analysis with rainbow trout (Oncorhynchus mykiss) and Arctic charr (Salvelinus alpinus). Heredity 94: 166-172.

Riddell BE, Leggett WC (1981). Evidence of an adaptive basis for geographic variation in body morphology and time of downstream migration of juvenile Atlantic salmon (Salmo salar). Can J Fish Aquat Sci 38: 308-320.

Riddell BE, Leggett WC, Sanders RR (1981). Evidence of adaptive polygenic variation between two populations of Atlantic salmon (Salmo salar). Can J Fish Aquat Sci 38: 321-333.

Rise ML, von Schalburg KR, Brown GD, Mawer MA, Devlin RH, Kuipers N et al. (2004). Development and application of a salmonoid EST database and CDNA microarray: data mining and interspecific hybridization characteristics. Genome Res 14: 478-490.

Rohlf FJ (2002). Geometric morphometrics in systematics. In: Macleod N, Forey P (eds). Morphology, Shape and Phylogenetics. Taylor \& Francis: London, pp 175-193.

Rohlf FJ (2005). tpsRegr, shape regression, version 1.31. Department of Ecology and Evolution, State University of New York at Stony Brook USA.

Rohlf FJ (2006). tpsDig2, digitizes landmarks, version 2.04. Department of Ecology and Evolution, State University of New York at Stony Brook USA.

Ron M, Weller JI (2007). From QTL to QTN identification in livestock-winning by points rather than knock-out: a review. Anim Genet 38: 429-439.

Seaton G, Haley CS, Knott SA, Kearsey M, Visscher PM (2002). QTL express: mapping quantitative trait loci in simple and complex pedigrees. Bioinformatics 18: 339-340.

Slate J (2005). Quantitative trait locus mapping in natural populations: progress, caveats and future directions. Mol Ecol 14: 363-379.

Solem Ø, Berg OK, Kjøsnes AJ (2006). Inter- and intrapopulation morphological differences between wild and farmed Atlantic salmon juveniles. J Fish Biol 69: 1466-1481.

Tang K, Fu DJ, Julien D, Braun A, Cantor CR, Koster H (1999). Chip-based genotyping by mass spectrometry. Proc Nat Acad Sci USA 96: 10016-10020.

Tao W, Boulding EG (2003). Associations between single nucleotide polymorphisms in candidate genes and growth rate in Arctic charr (Salvelinus alpinus L.). Heredity 91: 60-69.

Wright Jr JE, Johnson K, Hollister A, May B (1983). Meiotic models to explain classical linkage, pseudolinkage, and chromosome pairing in tetraploid derivative salmonids genomes. Isozymes Curr Top Biol Med Res 10: 239-260.

Supplementary Information accompanies the paper on Heredity website (http://www.nature.com/hdy) 